\title{
Assessing Public Transportation Vulnerability to Sea Level Rise: A Case Study Application
}

\author{
Dr. Michelle Oswald, Christian Treat \\ Bucknell University
}

\begin{abstract}
The potential for sea level rise inundation of critical transportation infrastructure rises as the threat of climate change continues. Inundation of public transportation including railroads and bus routes, specifically those located in low-lying coastal areas, are vulnerable to these impacts. Therefore, identifying vulnerable facilities in order to implement adaptation planning practices is essential to protecting these facilities and avoiding impacts on mobility. This research focuses on the application of the Transit Inundation Modeling Method (TIMM) to a transit network (railways and bus routes) in Philadelphia County, Pennsylvania. TIMM is developed based on the need to identify transit infrastructure systems that are vulnerable to sea level rise using Geographic Information Systems (GIS). Applying TIMM to a real-world transit network provides an example for how transit agencies throughout the nation can begin to identify at-risk links and nodes based on potential sea level rise inundation levels.
\end{abstract}

\section{Introduction}

As climate change continues to threaten both natural and built environments, the risk of impact to public transportation infrastructure rises (FTA 2011). Scientific studies predict that sea level rise will accelerate and, therefore, transportation infrastructure along the coast continues to be vulnerable to inundation (Koetse 
and Rietveld 2009). Increasing demands on public transportation systems suggest the need for evaluating the potential risk and impacts associated with coastal, lowlying public transportation facilities (Trilling 2005).

Public transportation provides a number of benefits, both environmental and socio-economic, in addition to providing mobility for those who are unable to drive. Currently, public transit operators provide approximately 10 billion trips per year in the United States (FTA 2011). A relatively new stressor, climate change, and the associated sea level rise can lead to increased flooding of subway tunnels, rail tracks, maintenance facilities, bus routes, and intermodal facilities, directly impacting transit-dependent populations.

Although interest in transportation and climate change impacts is rising, discussion and efforts are focused primarily on mitigation or reducing greenhouse gas (GHG) emissions and other contributions to global warming (Valsson and Ulfarsson 2009). Mitigation efforts such as advances in fuel technology and vehicle efficiency are being implemented; however, mitigation efforts are not timely enough to remove all potential impacts associated with global warming (Pew Center on Global Climate Change 2008). As a result, identifying vulnerabilities and implementing adaptation practices that support changes in infrastructure are necessary to reduce vulnerabilities and avoid potential impacts such as sea level rise inundation (Oswald et al. 2012).

\section{Objectives}

The primary objective of this research is to apply and evaluate the process of the Transit Inundation Modeling Method (TIMM) to a real-world transit network. TIMM is used to identify transit infrastructure systems that are vulnerable to sea level rise using GIS. Based on a review of existing modeling strategies and a needs assessment, TIMM developed by Oswald and Treat (2013) with the goal of assisting transit agencies with the initial step of adapting, focusing on identifying at-risk links and nodes based on various sea level rise inundation levels. The step-by-step method is described in detail based on its application to a transit network (railway, bus routes, and bus stops) in Philadelphia County, Pennsylvania. Results of the application are used not only to promote adaptation activities within the case study region, but to provide recommendations for future case study applications.

This real-world network application of TIMM is completed with the goal of evaluating the method's applicability, relevance, and repeatability for transportation infrastructure throughout the country. By using this method to identify vulner- 
abilities, transit agencies throughout the nation can begin to implement adaptation practices (elevate, relocate or protect) to existing facilities as well as plan for future transit projects.

\section{Research Method}

To complete the research objectives, a research framework (Figure 1) consisting of four parts was followed: (1) literature review, (2) TIMM development, (3) TIMM application, and (4) recommendations. The literature review is focused on adaptation concepts, sea level rise impacts, public transportation demand, and GIS modeling opportunities. Then, TIMM was developed based on the improvements that are needed to existing modeling or adaptation efforts. Next, TIMM was applied to Philadelphia County to serve as an example of how transit agencies can implement the method and begin to identify potential vulnerable facilities. This application (part 3) is the focus of this paper to show typical results of applying TIMM to a real-world network. Last, recommendations are proposed for improvements to the method as well as further applications of TIMM to other transit agencies.

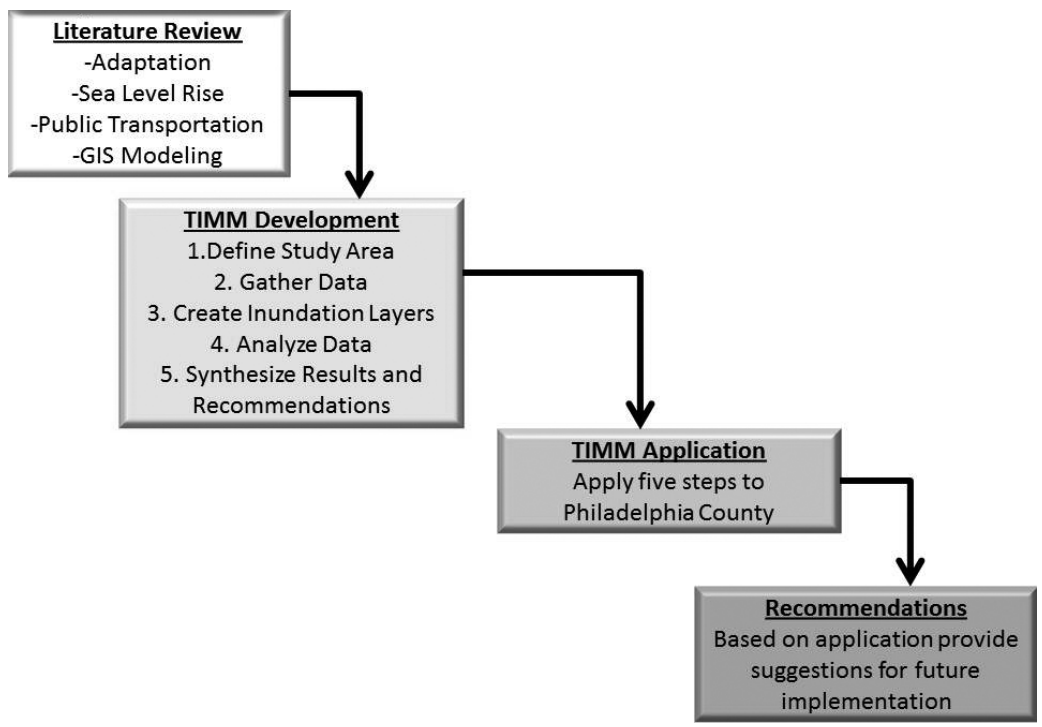

Figure 1. Research methodology

\section{Climate Change}

Scientific research suggests despite the uncertainty with future climate change projections, global warming is unequivocal (U.S. Global Change Research Program 
2009). Related alterations in average weather patterns, such as increases in heat waves and very hot days, increases in intense precipitation events, sea level rise, and increases in the frequency of extreme weather events, occur at a global scale and cause region-wide issues (CIER 2007). Projections, developed by the Intergovernmental Panel on Climate Change (IPCC) (2007) are useful in identifying possible impacts associated with varying emissions scenarios. However, current IPCC data indicate that these predictions may be underestimated (Rahmstorf 2007). Therefore, identifying potential risk and vulnerabilities associated with these changes is essential to avoid serious climate change impacts.

\section{Sea Level Rise}

Sea level rise is one of the most anticipated effects of climate change (Savonis et al. 2008). Although change in sea level has been continuous, it has been exascerbated by thermal expansion of warming ocean waters and deglaciation, causing oceans to rise at a rate much faster than in the past thousand years (Titus et al. 2009). The most serious effects of sea level rise include permanent inundation and temporary flooding due to storm surges, which will continue to worsen in frequency and intensity along with rising water levels.

As the United States population is markedly growing along the coasts, socioeconomic demands and the need for mobility rises (Culliton et al. 1990). Combined with an accelerating sea level rise, this creates regions in the United States that are extremely vulnerable to coastal hazards.

\section{Adaptation}

Mitigation efforts, or reducing GHG emissions, are not timely enough to remove all potential impacts associated with global warming (Pew Center on Global Climate Change 2008). Therefore, adaptation practices are needed to prepare and protect societies, economies, and the environment. The IPCC (2007) defines climate change adaptation as "the adjustment in natural or human systems in response to actual or expected climatic stimuli or their effects which moderates harm or exploits beneficial opportunities." In support of this definition, The Pew Center on Global Climate Change (2009) defines adaptation as "actions by individuals or systems to avoid, withstand, or take advantage of current and projected climate changes and impacts ... in order to decrease a system's vulnerability, or increase its resilience to impacts." These definitions emphasize the need to moderate or avoid harm as a result of climate change impact. 
To protect infrastructure from possible inundation, adaptation strategies are being developed and implemented. Possible adaptation strategies include elevation, relocation, strengthening through levees, seawalls and dikes, restricting further coastal development, and using natural ecosystems for protection (eco-engineering) (WILMAPCO 2011). The National Research Council (2010) aligned these general strategies with specific transportation impacts based on climatic impacts and identified the entities best suited to implement each option. Although research on the need for adaptation strategies is initiating, potential impacts on public transportation infrastructure continue to rise.

\section{Impact to Public Transportation}

Public transportation networks are critical infrastructure, as they are vital to maintaining mobility and accessibility (FTA 2011). Due to the threat of climate change, potential impacts related to rising sea level are posing risk to public transportation facilities. Subway tunnels, rail tracks, maintenance facilities, bus routes and stops, and intermodal facilities are vulnerable to inundation and, therefore, directly impact transit-dependent populations.

\section{Infrastructure Impacts}

From a planning perspective, identifying vulnerable infrastructure is essential to proactive and cost-effective decision-making. Due to railways often being located in low-lying areas, they are highly vulnerable to inundation (TRB 2008). Railways specifically are at-risk to flooding of underground tunnel and rail tracks, erosion of the rail base, and reduced clearance under bridges (TRB 2008). Tunnels, in particular, are highly vulnerable as a result of two impacts-the risk of flooding to entrances and vents and the hydraulic pressure on the walls of the tunnel increases as the water table rises (Titus 2002).

In addition to tunnels and at-grade railways, bridges are at-risk as well. As a result of frequent storm surge events and rising sea levels, high amounts of flowing water around bridges creates bridge scour. Increased water flow around the bases of bridges exacerbates the removal of soil at the foundations, compromising the integrity of the structure (FTA 2011). Most of the bridge failures in the United States occur as a result of scour impacts (AASHTO 2004). Therefore, the need for developing adaptation practices is crucial because infrastructure is prone to the direct effects of permanent inundation as well as the secondary impacts of sea level rise. 


\section{Current Efforts}

Transportation agencies have been limited in incorporating adaptation into their planning process as a result of real and perceived barriers (Oswald et al. 2012). However, recently, studies focused on identifying sea level rise impacts on transportation infrastructure are emerging. Research efforts such as Meyer and Weigel (2011) have promoted the use of an adaptive systems framework to manage transportation assets and Oswald et al. (2011) developed a Climate Change Adaptation Tool for Transportation (CCATT) to assist transportation agencies in integrating adaptation practices into long-range transportation plans. In addition to research, practical applications such as the Gulf Coast Study Phase 1 (U.S. DOT 2011a) focused on the process of identifying regional climate change impacts and developing risk assessment tools for use by transportation planners. In continuation of the research, the Gulf Coast Study Phase 2 includes a multimodal approach to determine the criticality of the transportation network in Mobile, Alabama, to climate change impacts (U.S. DOT 2011b). At the state-wide level, a similar study was implemented in Florida where the U.S. Department of Transportation (DOT) funded the development of a method to determine vulnerabilities specific to sea level rise on their infrastructure network (Berry 2012). More local studies on transit vulnerability have also been initiated, including applications to the New York City Transit Authority (City of New York 2011) as well as the Massachusetts Bay Transportation Authority (Kirshen et al. 2005).

To further refine the goals of the regional studies, national agencies such as the Federal Transit Administration (FTA) and the Federal Highway Administration (FHWA) are supporting projects. FTA is conducting pilot programs for transit agencies to begin implementing inundation modeling and adaptation practices. The pilot programs are located throughout the nation and include the Gulf Coast, Pennsylvania, Los Angeles, San Francisco, Seattle, Chicago, and Atlanta (FTA 2011). FHWA is also overseeing pilot programs for DOT's to implement their risk assessment framework for climate change adaptation.

\section{GIS Modeling}

Many of the regional assessments and studies incorporate the use of spatial analysis to identify vulnerabilities. For example, at the regional level, the Coastal Adaptation to Sea-Level Rise Tool (COAST), developed by NOAA Coastal Services Center (2012), combines inundation layers with employment, wages, and number of businesses to determine and visualize overall economic vulnerability in the Gulf Coast region (Merrill et al. 2010). Similarly, Colgan and Merrill (2008) estimated the 
economic cost of inundation in coastal communities in Maine using the hurricane forecasting model SLOSH (Sea, Lake, Overland Flow Surge from Hurricanes). For transportation planning, this scope is narrowed, as planners aim to identify specific lines and nodes vulnerable to inundation. For example, Oswald et al. (2012) conducted a transportation vulnerability study on Delaware focusing on the sea level rise impact on the $1-95$ corridor (rail, road, and bus routes). These modeling methods serve as the beginning of a more formalized process for using spatial analysis to determine vulnerabilities associated with sea level rise.

\section{Transit Inundation Modeling Method (TIMM)}

TIMM was developed with the goal of assisting transit agencies to begin adapting by identifying at-risk links and nodes based on various sea level rise inundation levels. TIMM is based on a five-step process that can be applied to transit agencies throughout the country, specifically in coastal areas. The process is repeatable, straightforward, GIS-based, and uses publically-available data. The five steps are listed and described below, however for an explanation of how TIMM was developed refer to Oswald and Treat (2013). In addition, through the case study application, the five steps are explained as they are applied to Philadelphia County, PA.

\section{Define Study Area}

The study area is defined based on proximity to coastal zones, jurisdiction of the transit agency, and extent of the transportation network. Facilities at-risk are those that are most exposed to sea level rise hazards and necessitate planning strategies and application of TIMM.

2. Gather Data

TIMM is based on publicly-available data that are accessible from agency websites, local university websites, and data clearinghouses such as the U.S. Census Bureau. Information that is relevant for assembling the maps includes county boundary shapefiles, local hydrology, and relevant transportation infrastructure networks. In preparation for the next step-creation of inundation layers-elevation data are available from the U.S. Geological Survey (2012) National Elevation Dataset (NED). Based on the extent of the study area, the resolution of each dataset must be checked to ensure accurate analysis.

3. Create Inundation layers

The elevation data are based on a digital elevation model (DEM), which can be used for extracting inundation layers. DEMs capture elevation informa- 
tion on a cell-by-cell basis and, for the purposes of projecting inundation scenarios, a cell is considered inundated if its elevation value is less than or equal to the projected sea level. However, to prevent inland areas from becoming inadvertently mapped as flooded, hydrological connectivity was accounted for by selecting cells with the desired elevation value and were located in connection to ocean (coastal water) cells. Hydrologic connectivity can be restricted to cells connected in the four cardinal directions ("four-side" rule) or in the cardinal and diagonal directions ("eight-side" rule). This method uses the eight-side rule when modeling sea level rise to show maximum potential inundation (Gesch 2009). This enables flooding that follows more accurate hydrologic behavior on the surface while representing maximum potential inundation. Inundation layers were added to the basemaps for use in step 4, data analysis.

4. Data Analysis

The infrastructure (railways, bus routes and bus stops) was symbolized based its location relative to each sea level rise projection in order to reflect its vulnerability to inundation. Thus, a qualitative scale was created where infrastructure located within the 1 meter inundation area has a greater vulnerability than infrastructure located only within the 5 meter inundation area. The impact of each inundation scenario was quantified by extracting infrastructure at each inundation scenario and calculating the summary statistics (mileage or number of stops) for each aspect of the transportation network.

5. Results and Recommendations

Identification of vulnerabilities in the transportation network is an iterative process that allows for proactive decision-making by the transit agency. In addition to information on the location of infrastructure and its relation to projected sea level rise, prioritization of projects can be supplemented by ridership information, facility demand, and facility cost to allow for holistic and sustainable decision-making.

\section{Application of TIMM}

To determine the applicability and relevance of the methodology, TIMM was applied to a real-world transit network in Philadelphia County. This location was selected due to its coastal proximity as well as the Southeastern Pennsylvania Transportation Authority's (SEPTA) proactive interest in adaptation planning. Currently, SEPTA is one of the seven agencies included in FTA's transit climate change adaptation assessment pilots (FTA 2011). 
The case study application of TIMM included applying each of the five steps to the rail and bus network in the county based on SETPA's jurisdiction. Therefore, this application reflects the process that a transit agency, such as SEPTA, would implement to begin identifying vulnerabilities using a spatial analysis method such as GIS.

\section{Methodology}

The five-step process of TIMM, as defined previously, is applied to the case study region. Each step is defined in detail, and the results are spatially displayed. To complete the application, data were processed and layers were created using ArcGIS 10 and the Spatial Analyst Extension (ESRI 2011).

\section{Define Study Area}

The study area selected for the application of TIMM was Philadelphia County, located along 20 miles of the Delaware River. Relevant sea level rise characteristics in this area and in the Delaware estuary have been documented, including increasing saline levels, flooding of hazardous waste sites, and a decline of public access to the shore line (DVRCP 2004). Along with the ecological and social issues of sea level rise in the Delaware River, inundation also poses significant economic impacts, especially to the transportation sector. SEPTA has an extensive transportation network, covering a surface area of 2,202 square miles, an annual ridership of more than 300 million, 143 routes, and 2,803 revenue vehicles (SEPTA 2012). In addition, it has developed a five-year Strategic Business Plan for 2010-2014 focused on several objectives, including sustaining the financial health of the agency, maintaining transportation access for low-income residents to and from their jobs, prevention of accidents and property damage, increasing frequency and extending service, and rebuilding existing lines and links (SEPTA 2009). Inundation from sea level rise would not only impact this widespread network, but also would compromise these established goals. Furthermore, SEPTA has also identified environmental planning as a current and future goal and has launched an awareness campaign to address this issue. Thus, the methodology not only targets vulnerabilities of the network, but also coincides with the progressive goals of the transit agency.

\section{Gather Data}

The base layers of the maps include the county boundaries and local hydrology of the Delaware River. These are vector files that are accessed via the Pennsylvania Geospatial Data Clearinghouse (PASDA 2012). Transportation infrastructure data were provided by SEPTA and include vector 
point and multi-line features of bus stops, bus routes, and rail lines. The bus route data also include ridership information based on total passengers and the total number of trips for each individual bus route. Together, the county boundary, local hydrology, and transportation layers were overlaid to create three different maps for each infrastructure type (railway, bus routes, and bus stops). Elevation information for the digital elevation model was obtained from the National Elevation Dataset at the 1/9 arcsecond resolution (U.S. Geologic Survey 2010). This is the highest quality resolution available in a raster format, where each cell value represents an elevation interval of 1 meter.

\section{Create Inundation Layers}

The DEM provided the basis for creating sea level rise scenarios. The inundation levels used reflect a range of existing projections from 1 to 5 meters, using an interval of 1 meter. To extract pertinent elevation values, the raster was first reclassified into an output of land and sea level rise increments, where the sea level rise projections reflect the desired range of scenarios $(0,1,2,3,4$, and 5 meters), and the land value includes all elevations over 5 meters. Using this output, hydrological connectivity was established to create a more accurate model of inundation. The eight-side connectivity rule was used to eliminate any low-lying areas that would be considered flooded, such as inland lakes, which are not connected to the sea. After establishing hydrological connectivity, the output was then reclassified into land values and true sea level inundation extents. Next, to use the inundation layers in conjunction with the transportation infrastructure layers, the raster was converted into a vector. This was then added onto the inundation layers created in step 2 to analyze and identify vulnerable infrastructure.

\section{Analyze Data}

The impact of different inundation scenarios was symbolized by color gradation to represent the degree of vulnerability to inundation. The vulnerability of each link/node is defined based on the scale of 1 meter rise (high vulnerability) to 5 meter rise (low vulnerability), and infrastructure was extracted at each inundation level. These inundated infrastructure layers were added to their respective maps.

Figures 2 through 4 are extent maps of southern Philadelphia County showing inundation impacts to the transit facilities. Southern Philadelphia County is highlighted as it is the most vulnerable to sea level rise inundation throughout the county. Figure 2 shows the inundated rail network, 
Figure 3 shows the inundated bus routes including ridership, and Figure 4 shows the inundated bus stops. The ridership information is useful for prioritization of at-risk infrastructure, and routes are symbolized based on number of passengers per trip.

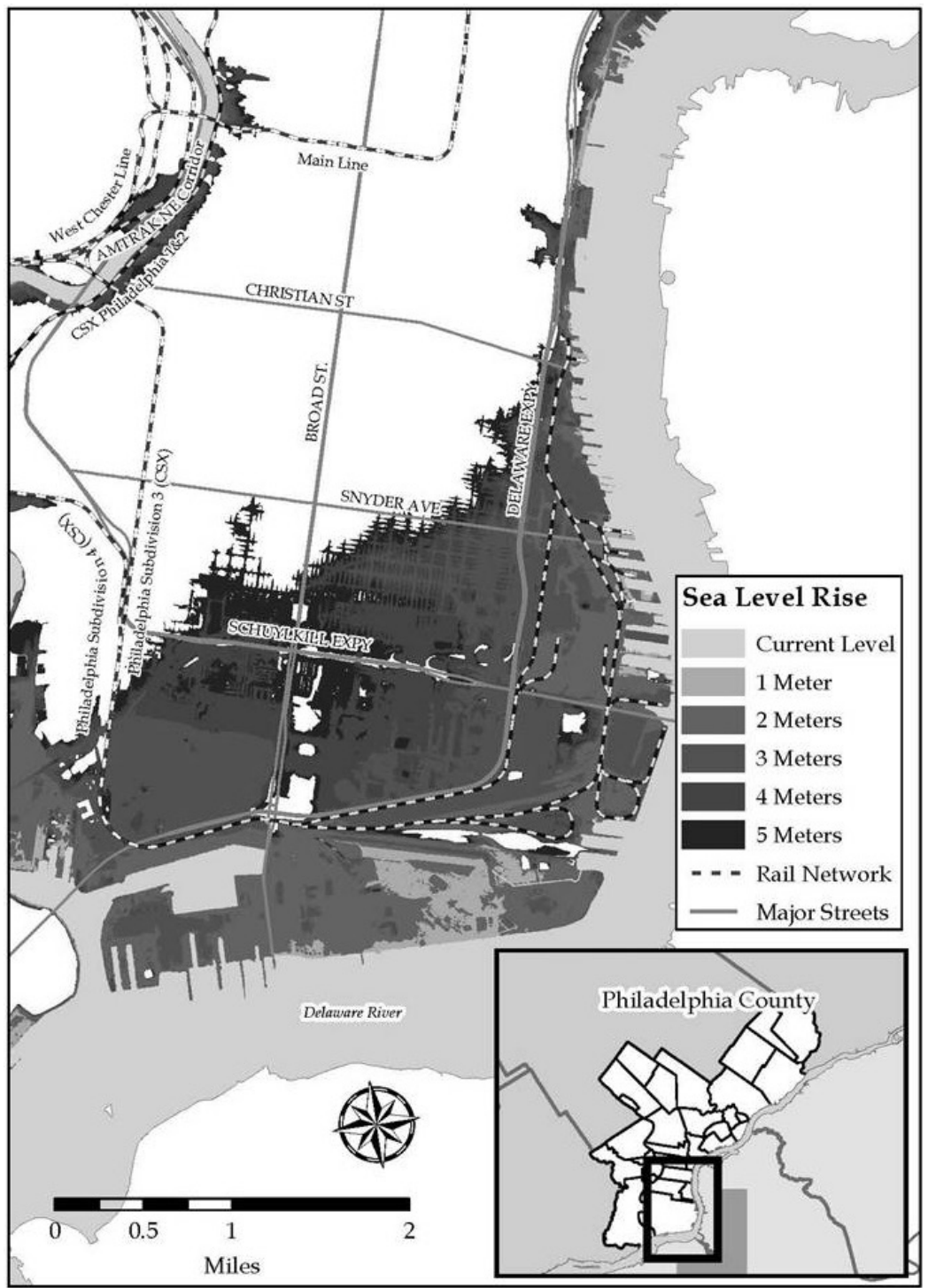

Source: SEPTA 2012

Figure 2. Extent map of inundated rail network in Philadelphia County 


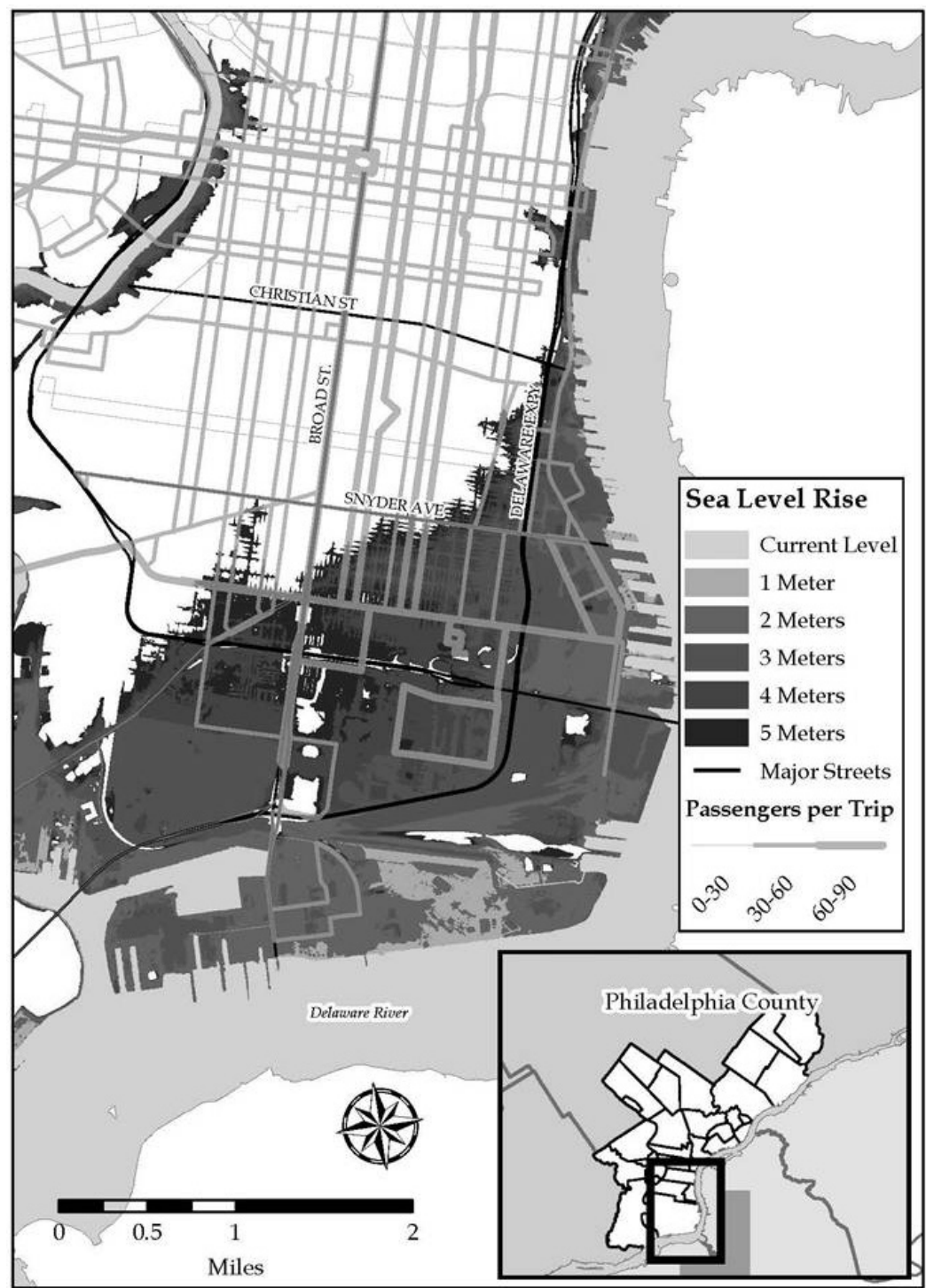

Source: SEPTA 2012

Figure 3. Extent map of inundated bus routes in Philadelphia County 


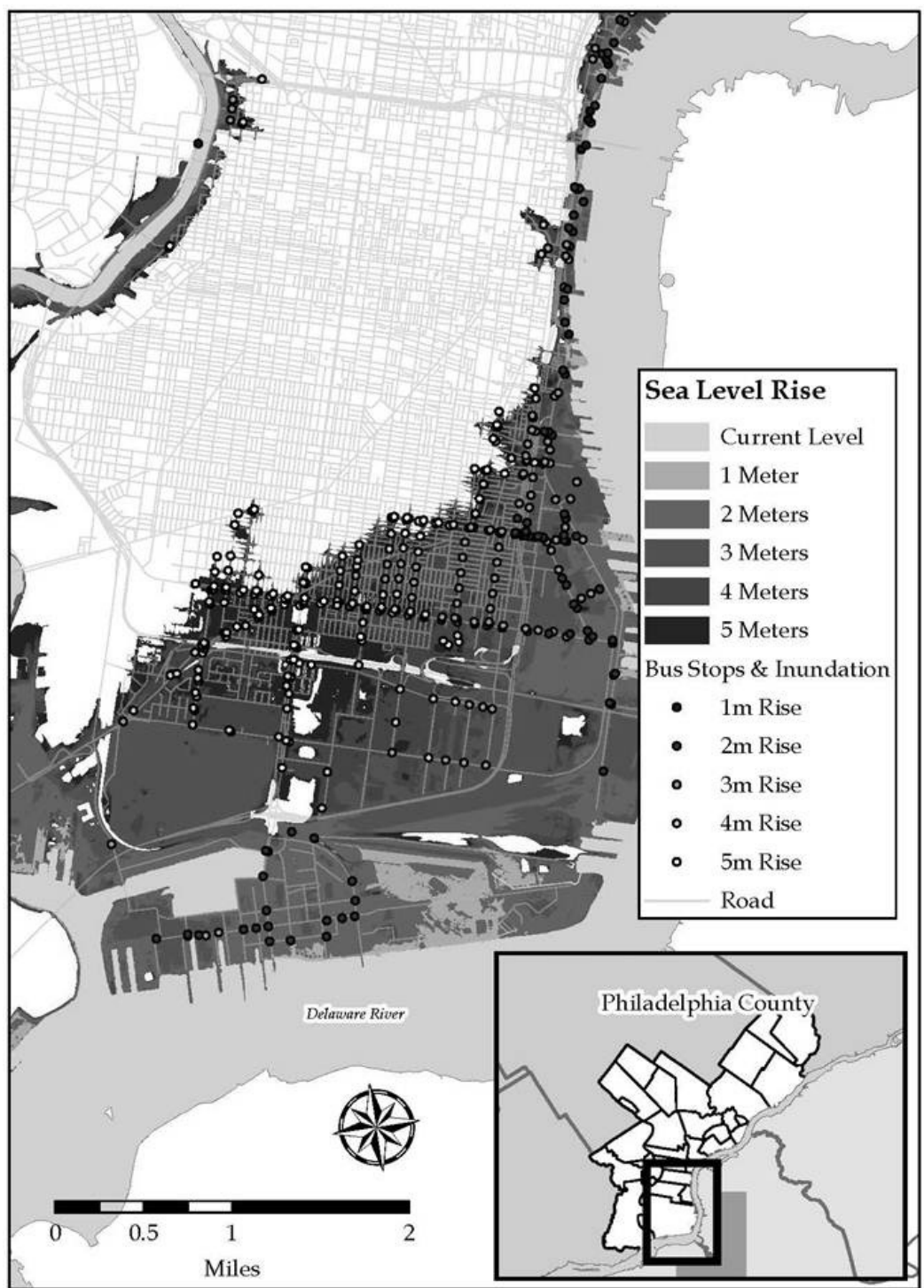

Source: SEPTA 2012

Figure 4. Extent map of inundated bus stops in Philadelphia County 
Summary statistics were calculated for each map to quantify the impact of each inundation scenario on the transportation network. Using the inundation layers and features in the GIS attribute tables allowed for the mileage, or count of infrastructure (number of stops), within each inundation to be calculated. For example, the total miles of rail network inundated at each level, as well as cumulatively, were calculated. This process was also implemented for bus routes and bus stops as shown in Table 1.

\section{Table 1. Vulnerable Infrastructure Based on Sea Level Rise in Philadelphia County}

\begin{tabular}{|c|l|c|c|c|c|c|}
\hline & \multicolumn{1}{|c|}{ Sea Level Rise } & $\mathbf{1 m}$ & $\mathbf{2 m}$ & $\mathbf{3 m}$ & $\mathbf{4 m}$ & $\mathbf{5 m}$ \\
\hline \multirow{3}{*}{ Bus routes } & Change in miles & 3 & 46 & 39 & 49 & 40 \\
\cline { 2 - 7 } & Cumulative miles & 3 & 49 & 88 & 137 & 177 \\
\hline \multirow{3}{*}{ Bus stops } & Change in \# of stops & 7 & 152 & 170 & 181 & 203 \\
\cline { 2 - 7 } & Cumulative total & 7 & 159 & 329 & 510 & 713 \\
\hline \multirow{3}{*}{ Rail } & Change in miles & 1.4 & 17.1 & 10 & 2.3 & 2.4 \\
\cline { 2 - 7 } & Cumulative miles & 1.4 & 18.5 & 28.5 & 30.8 & 33.2 \\
\hline \multirow{3}{*}{ Land } & Change in acres & 880 & 4,612 & 4,421 & 2498 & 2,055 \\
\cline { 2 - 7 } & Cumulative acres & 880 & 5,492 & 9,033 & 11,531 & 13,586 \\
\hline
\end{tabular}

Acreage of land inundated was also included in the analysis. The inundation layers created in step 3 include the original water features; therefore to accurately calculate the inundation area, hydrology features for this layer were eliminated. Using a similar approach to calculating the vulnerable infrastructure based on inundation levels, the acreage of land inundated was calculated for each level as well as cumulatively, as shown in Table 1.

\section{Synthesize Results and Recommendations}

Based on the projected inundation levels, public transportation infrastructure within Philadelphia County is at risk of flooding, even at the lower sea level rise levels. The difference between the amount of infrastructure impacted at 1 meter and 2 meter projections is substantial and, based on scientific research, these sea level rise projections may be conservative. Based on the spatial analysis results, the southern region of Philadelphia is most notably at-risk for inundation. Although comparisons between links and nodes can be made visually, more information about how to prioritize current and future projects is needed. More specifically, a prioritization index, including other factors such as ridership and cost, can be established 
to plan future adaptation projects. Ridership information is included in the bus routes extent (Figure 3) to compare infrastructure based on both sea level rise vulnerability as well as user demand. Including factors, such as ridership, can provide more holistic decision-making when prioritizing future adaptation projects.

\section{Reflection}

Modeling vulnerabilities in transportation infrastructure due to sea level rise requires accurate elevation data and a detailed transportation network. It is recognized that spatial information is not available for every network; however, following a process such as TIMM, which is based on publically-available sources, can allow agencies to begin using GIS for adaptation planning.

While more accurate DEMs can be derived from contour maps, the hydrologic connectivity method requires knowledge of GIS software; therefore, it is encouraged that agencies have expertise in this area. Furthermore, the transportation data may be agency-specific and include infrastructure owned by only one transit agency, rather than assets from all agencies in the region. The case study region features an area that is within SEPTA's jurisdiction, but several rail tracks and rail yards owned by other companies were not included in the data. In future applications, more holistic network data can allow for multi-jurisdictional analysis. In addition, more detailed local factors that influence storm surge impacts are not included. These variables, which have the potential to alter flooding, include location of storm water facilities, runoff impacts, and permeability of the soil. As inundation modeling methods improve and include local impacts, TIMM can be further developed to allow for more accuracy in identifying potential public transportation vulnerabilities.

Overall, applying TIMM is useful for the transit agency because it allows for the identification of potential at-risk facilities based on a number of scenarios. Identifying these facilities sooner rather than later can lead to proactive and holistic decision-making for adaptation planning.

\section{Conclusion}

Increasing demands on public transportation systems suggest the need for evaluating the potential risk and impacts associated with coastal, low-lying public transportation facilities (Trilling 2005). The relatively new stressor, climate change, and associated sea level rise, can lead to increased flooding of subway tunnels, rail 
tracks, maintenance facilities, bus routes, and intermodal facilities, directly impacting transit-dependent populations. Therefore, adaptation planning and practices are needed to prepare and protect these facilities from inundation.

The Transit Inundation Modeling Method is developed for adaptation planning, specifically to identify transit infrastructure systems that are vulnerable to sea level rise using GIS. The real-world network application of TIMM to Philadelphia County was completed with the goal of evaluating the method's applicability, relevance, and repeatability for transportation infrastructure throughout the country. Although there are limitations associated with data availability and inundation modeling constraints, this application serves as a foundation for using spatial analysis for transit adaptation planning. By using this method to identify vulnerabilities, transit agencies throughout the nation, similar to SEPTA, can begin to implement adaptation practices (elevate, relocate, or protect) to existing facilities as well as plan for future transit projects.

\section{References}

AASHTO (American Association of State Highway and Transportation Officials). 2004. AASHTO LRFD Bridge Design Specifications. Washington D.C.: AASHTO.

Berry, L. 2012. Development of a methodology for the assessment of sea level rise impacts on Florida's transportation modes and infrastructure. Florida Department of Transportation, http://www.dot.state.fl.us/research-center/ Completed_Proj/Summary_PL/FDOT_BDK79_977-01_rpt.pdf.

CIER (Center for Integrative Environmental Research). 2007. The U.S. economic impacts of climate change and cost of inaction. University of Maryland, http://www.cier.umd.edu/documents/US\%20Economic\%20Impacts\%20of\%20 Climate\%20Change\%20and\%20the\%20Costs\%20of\%20Inaction.pdf. Accessed May 7, 2010.

City of New York. 2011. PlaNYC: Climate Change. http://nytelecom.vo.Inwd.net/ 015/agencies/planyc2030/pdf/planyc_2011_climate_change.pdf.

Culliton T. J, M. A. Warren, T. R. Goodspeed, D. G. Remer, C. M. Blackwell, and J. J. McDonough III. 1990. 50 Years of Population Change along the Nation's Coasts: 1960-2010. Rockville, MD: National Ocean Service, National Oceanic and Atmospheric Administration (NOAA). 
DVRPC (Delaware Valley Regional Planning Commission). 2004. Sea level rise impacts in the Delaware Estuary of Pennsylvania. Pennsylvania Coastal Zone Management Program, http://www.dvrpc.org/reports/04037.pdf.

ESRI (Environmental Systems Research Institute). 2011. ArcInfo ArcMap Desktop. Redlands, CA: ESRI.

FTA (Federal Transit Administration). 2011. Announcement of project selection: Transit climate change adaptation pilots. U.S. Department of Transportation, http://fta.dot.gov/sitemap_14228.html.

Gesch, D. B. 2009. Analysis of lidar elevation data for improved identification and delineation of lands vulnerable to sea-level rise. Journal of Coastal Research 53: 49-58.

IPCC. 2007. Climate Change 2007: The Physical Science Basis. Contribution of Working Group I to the Fourth Assessment Report of the Intergovernmental Panel on Climate Change (Summary for Policymakers). [Solomon, S., D. Qin, M. Manning, Z. Chen, M. Marquis, K.B. Averyt, M. Tignor, and H.L. Miller (eds.)]. Cambridge University Press, Cambridge, UK and New York, NY.

IPCC Coastal Zone Management. 1992. A common methodology for assessing vulnerability to sea level rise. 2nd revision. In Global Climate Change and the Rising Challenge of the Sea. The Hague, Netherlands: Ministry of Transport, Public Works and Water Management.

Kirshen, P., M. Ruth, and W. Anderson. 2005. Climate change in metropolitan Boston. New England Journal of Public Policy 20(2), Article 7. Retrieved from http:// scholarworks.umb.edu/nejpp/vol20/iss2/7.

Koetse, M. J., and P. Rietveld. 2009. The impact of climate change and weather on transportation: An overview of empirical findings. Transportation Research Part D 14: 205-221.

Meyer, M., and B. Weigel. 2011. Climate change and transportation engineering: Preparing for a sustainable future. Journal of Transportation Engineering 137 (6): 393-403.

NOAA Coastal Services Center. 2012. Sea level rise and coastal flooding impact viewer. Retrieved from http://www.csc.noaa.gov/digitalcoast/tools/slrviewer/ status.jpg. 
Oswald, M., and C. Treat. 2013. Identifying sea level rise vulnerability using GIS: development of a transit inundation modeling method. International Journal of Geoinformatics 9(1): 1-10.

Oswald, M., S. McNeil, D. Ames, and W. Mao. 2012. Transportation planning in response to climate change: Methods and tools for adaptation. Delaware Transportation Research Board Conference Proceedings, 2012 Annual Meeting, http://amonline.trb.org/1sf7k2/1sf7k2/1.

Pew Center on Global Climate Change. 2008. Adaptation planning: What U.S. states and localities are doing. http://www.pewclimate.org/docUploads/ State_Adapation_Planning_04_23_08\%20_2_.pdf.

Rahmstorf, S., A. Cazenave, J. A. Church, J. E. Hansen, R. F. Keeling, D. E. Parker, and R. C. J. Sommerville. 2007. Recent climate observations compared to projections. Science 316, 706, doi: 10.1126/science.1136843.

SEPTA. 2012. Resource Center Research and Statistics. SEPTA NPT. http://www. septa.org/fares/npt/resource-center.html.

SEPTA. 2009. Five-Year Strategic Business Plan for 2010-2014. http://www.septa.org/ reports/pdf/strategic.pdf.

Titus, J., K. E. Anderson, D. R. Cahoon, D. B. Gesch, S. K. Gill, B. T. Gutierrez, E. R. Thieler, and S. J. Williams. 2009. Coastal sensitivity to sea-level rise: A focus on the mid-Atlantic region. U.S. climate change science program and the subcommittee on global change research: Synthesis and assessment product 4.1.

TRB (Transportation Research Board). 2008. Potential impacts of climate change on U.S. Transportation. TRB Special Report 290. National Research Council of the National Academies, Washington DC.

Trilling, D.R. 2002. Notes on transportation into the year 2025. Paper presented at The Potential Impacts of Climate Change on Transportation Research Workshop, Washington, DC., October 1-2.

U.S. Geologic Survey. 2010. The National Elevation Dataset. U.S. Department of the Interior, http://seamless.usgs.gov/faq_listing.php.

U.S. Global Change Research Program. 2009. Global climate change impacts in the United States. http://www.globalchange.gov/publications/reports/scientificassessments/us-impacts. 
U.S. DOT. 2011a. Impacts of climate change and variability on transportation systems and infrastructure: The Gulf Coast Study. Final report and synthesis product 4.7. http://www.climatescience.gov/Library/sap/sap4-7/final-report/.

U.S. DOT. 2011b. Impacts of climate change and variability on transportation systems and infrastructure: Gulf Coast Study phase 2, task 1: Assessing infrastructure criticality for Mobile, Alabama. Final Technical Memo, Task 1. http://www. fhwa.dot.gov/environment/climate_change/adaptation/ongoing_and_current_research/gulf_coast_study/phase_2/gulfcoast2.pdf.

Valsson, T., and G. F. Ulfarsson. 2009. Adaptation and change with global warming. University of Iceland. http://www.trb.org/marineboard/AM09/270Valsson. pdf. Accessed June 20, 2009.

\section{About the Authors}

Dr. Michelle Oswald (michelle.oswald@bucknell.edu) is a LEED AP and an Assistant Professor at Bucknell University in Civil and Environmental Engineering. She completed her Ph.D. in Civil Engineering at the University of Delaware, specializing in sustainable transportation planning. She received a B.S. in Civil Engineering from Lafayette College and M.C.E. and M.A. degrees in Urban Planning from the University of Delaware.

Christian TREAT (cat022@bucknell.edu) is a senior majoring in animal behavior at Bucknell University. In the summer of 2012, he received a grant sponsored by the Andrew W. Mellon Foundation for this research project with the goal of integrating spatial thinking into environmental and engineering based projects. 